\title{
ऽ0
}

O MATRIARCADO E O LUGAR SOCIAL DA MULHER EM ÁFRICA: Uma abordagem afrocentrada a partir de intelectuais africanos

\section{Matriarchy and the social place of}

women in Africa: An afrocentrated approach from African intellectuals

\author{
Fernanda Chamarelli de Oliveira \\ Pontifícia Universidade Católica do Rio de \\ Janeiro (PUC-RJ) \\ fchamarelli29@gmail.com
}

DOI: https://doi.org/10.22481/odeere.v3i6.4424

\section{Resumo}

$\mathrm{O}$ artigo pretende realizar um debate sobre os fatores sociais, culturais e históricos presentes nas sociedades africanas précoloniais que contribuíram para sua forma de organização matrilinear. Partindo da análise das obras de três autores africanos, sendo eles Cheik Anta Diop, Ifi Amadiume e Oyeronke Oyewumi, assim como realizando a partir da produção destes um debate historiográfico centrado na compreensão dos fatores presentes na organização social que conferiam um elevado status social e político às mulheres e o papel por elas exercido nas sociedades matrilineares africanas. Através da proposta deste debate, buscaremos compreender como as categorias de gênero e mulher estão presentes nestes discursos e as questões relacionadas ao uso de conceitos ocidentais em realidades diferentes, como no caso das sociedades africanas. Para levantar tais questionamentos, utilizaremos uma perspectiva afrocentrada, a fim de buscar análises e interpretações que visem demonstrar a centralidade do africano como sujeito de sua história e cultura.

$\begin{array}{lr}\text { Palavras-chave: } & \text { Mulher; } \quad \text { Gênero; } \\ \text { Matrilinearidade; } & \text { Matrifocalidade; } \\ \text { Afrocentrismo. } & \end{array}$

Abstract: The article intends to hold a debate on the social, cultural and historical factors present in pre-colonial African societies that contributed to its matrilineal form of organization. Starting from the analysis of the works of three African authors, such as Cheik Anta Diop, Ifi Amadiume and Oyeronke Oyewumi, as well as considering the production of a historiographic debate having relation with their works and centered on the understanding of the factors present in the social organization that confer a high 
social and political status for women and the role they played in African matrilineal societies. Through the proposal of this debate, we will try to understand how the categories of gender and woman are present in these discourses and the issues related to the use of Western concepts in different realities, as in the case of African societies. In order to raise such questions, we will use an afrocentrated perspective in order to seek analyzes and interpretations aimed at demonstrating the centrality of the African as the subject of his / her history and culture.

Keywords: Woman; Gender; Matrilinearity; Matrifocality; Afrocentrism.

\section{Introdução}

O presente trabalho propõe um debate acerca das concepções de matriarcado e matrilinearidade, bem como dos conceitos de mulher e gênero a partir dos discursos de intelectuais africanos. O enfoque do debate será dado nas pesquisas realizadas por três intelectuais, sendo eles Cheik Anta Diop, Ifi Amadiume e Oyeronke Oyewumi. Utilizaremos também o debate historiográfico que foi realizado a partir destes intelectuais por outros pesquisadores, entre eles Carlos Moore, Isabel Casimiro, Elisa Larkin do Nascimento, Jìmí Adésínà, Cleonora Hudson-Weems, Molefi Asante e Nah Dove.

Nosso objetivo é reconhecer fatores sociais, políticos, econômicos e culturais presentes nas sociedades africanas na antiguidade que contribuíram para sua forma de organização matriarcal e que conferiam um elevado status social e político às mulheres e ao papel por elas exercido nestas sociedades. Nossa abordagem pretende trazer um olhar diferente sobre o matriarcado em relação àquele que foi abordado por pesquisadores e antropólogos pré-coloniais, que o associavam apenas a situações onde as mulheres se encontravam ocupando posições de autoridade política e o viam como uma forma primitiva e promíscua de organização social.

Pretendemos com esta pesquisa apresentar um discurso que considere as questões, fontes e conhecimentos endógenos de sociedades africanas em seu período pré-colonial de desenvolvimento. A partir do debate entre os intelectuais africanos citados, buscamos representar uma apropriação crítica do tema em questão, e uma produção epistêmica das relações de gênero que rompa com as narrativas de produção ocidental, considerando o local etnográfico específico de sua pesquisa, bem como as relações econômicas, sociais, políticas e culturais ali presentes.

A partir da reflexão do filósofo africano Paulin Hountond ${ }^{1}$, consideramos a relevância da busca por investigadores africanos de uma tradição de conhecimentos que tenham como base questões desencadeadas pelas próprias sociedades africanas, sendo sua investigação assim por elas

\footnotetext{
${ }^{1}$ HOUNTONDJI, Paulin J. Conhecimento de África, conhecimento de africanos: duas perspectivas sobre os estudos africanos. Revista Crítica de Ciências Sociais (Coimbra), $\mathrm{n}^{\circ}$ 80, 2008.
} 
determinada direta ou indiretamente. Para o autor os conhecimentos sobre os estudos africanos estão inseridos em um projeto de transformação, porém estes devem ter sua base em África, sendo desenvolvidos por africanos e não se tratando somente de estudos sobre a África.

Partiremos da proposta enunciada por Cheik Anta Diop, em sua obra "The cultural unity of Black Africa - the domains of patriarchy and of matriarchy in classical antiquity" (1989), onde para além das diversidades e múltiplas histórias que se desenvolvem no continente africano, é possível buscar uma unidade cultural africana, que teria como base a organização matriarcal, que se apresentaria como uma similitude entre as sociedades africanas e seus sistemas institucionais que se encontram no continente africano. O continente africano, para Diop, foi um dos berços de desenvolvimento da organização matriarcal, sendo o patriarcado introduzido apenas com a penetração do islamismo no continente. Mesmo assim, Diop $^{2}$ defende que este, no entanto, não penetrou profundamente na base do sistema matriarcal ${ }^{3}$.

Desta forma, nossa proposta de debate sobre o matriarcado africano relaciona-se com a abordagem afrocentrada ${ }^{4}$ proposta por Asante, se caracterizando pelo reposicionamento do africano como sujeito de sua própria história, como agente de ideias, transformação e cultura e também estabelecendo uma crítica às interpretações cujas categorias e conceitos sejam utilizados a partir de um pensamento hegemônico cultural europeu. A partir desta abordagem, compreende-se que existe uma ampla diversidade cultural no continente africano, considerando aqui primordialmente seu período pré-colonial, mas que ainda assim é possível traçar uma similitude entre os sistemas institucionais existentes. Essa unidade cultural desta forma pensada pressupõe uma transmissão intergeracional de valores e crenças nas sociedades, uma difusão de visões de africanidade.

Partindo, portanto, desta abordagem afrocentrada, levantaremos questionamentos e buscaremos informações e interpretações a partir de valores, atitudes e perspectivas africanas, para que possamos assim estabelecer novas percepções sobre a organização matriarcal desenvolvida na continente africano. Utilizaremos ao longo de nossa pesquisa exemplos do status

\footnotetext{
${ }^{2}$ DIOP. Cheik Anta. The cultural unity of Black Africa - the domains of patriarchy and of matriarchy in classical antiquity. Westbourne, Karnak house, 1989.

${ }^{3}$ Para embasar sua teoria do matriarcado relacionada ao continente africano, Cheik Anta Diop trabalha com a concepção de uma unidade cultural africana, onde haveria uma transmissão entre as gerações de valores e crenças, considerando as diferenças que foram impostas ao longo do tempo pelas dominações árabe e europeia.

${ }^{4} \mathrm{O}$ conceito de afrocentricidade foi elaborado em 1980, por Molefi Asante, a partir da publicação do livro Afrocentricidade: teoria de mudança social. O objetivo era uma conscientização em relação às opressões sofridas pelos africanos e também sobre a possibilidade de mudanças e conquistas. A afrocentricidade busca uma conscientização do africano como sujeito de sua própria história e uma análise das relações humanas partindo de interpretações que tenham como perspectiva uma nova orientação para os fatos.
} 
político e do lugar social ocupado pela mulher em civilizações da antiguidade, como a egípcia e a kushita, a fim de proporcionar informações que embasem o tema do matriarcado por nós discutido, e também como ligação a uma característica central do afrocentrismo que fundamenta sua análise no pensamento cultural da África clássica.

\section{O matriarcado e a matrilinearidade na obra de Cheik Anta Diop}

Cheik Anta Diop, escrevendo na década de 1950, período de intenso debate sobre o processo de independências no continente africano, destaca-se como um dos mais importantes pesquisadores sobre história da África. Diop 5 entende que é necessário haver uma valorização da historicidade das sociedades africanas e dentro também da concepção de estabelecer uma nova história para o continente África, desconectada do etnocentrismo até então predominante, trabalha com a concepção de uma unidade cultural africana, considerando as diferenças que foram impostas ao longo do tempo pelas dominações árabe e europeia. O autor busca a partir de suas pesquisas, demonstrar que o continente como berço das civilizações mais antigas, hipótese que foi bastante contestada no século em que ele desenvolve suas pesquisas.

O conceito de matriarcado associado à busca de explicações sobre as sociedades africanas já era utilizado por antropólogos coloniais desde a década de 1930. Diop teve acesso a pesquisas realizadas por antropólogos e suas visões sobre o matriarcado africano a partir das produções do Centro de Estudos da Guiné Portuguesa, bem como através dos discursos intelectuais produzidos pelo IFAN (Institut Français d'Afrique Noire) ${ }^{6}$. O matriarcado era por estes pesquisadores associado à poliandria, mostrando ser esta uma forma de organização promíscua. Estas pesquisas também associavam o matriarcado a posições de autoridade política ocupadas por mulheres e o colocava como um sistema oposto ao patriarcado. A matrilinearidade ${ }^{7}$ era reconhecida como justaposta ao matriarcado, gerando assim a concepção de que as sociedades que tinham esta forma de organização estariam em um estágio primitivo de evolução.

Conhecendo o acesso de Diop a estas fontes, podemos também reconhecer seus esforços em

\footnotetext{
${ }^{5}$ DIOP. Cheik Anta. The cultural unity of Black Africa - the domains of patriarchy and of matriarchy in classical antiquity. Westbourne, Karnak house, 1989.

${ }^{6}$ Cheik Anta Diop estabeleceu relações intelectuais com o IFAN na década de 1950, período em que se encontrava na França. Este instituto, criado em 1938, era uma iniciativa francesa de estudos sobre sua colônia, o Senegal. As produções intelectuais deste instituto possuíam grande proximidade com os estudos do posteriormente criado Centro de Estudos da Guiné Portuguesa, uma iniciativa portuguesa de incentivar a produção de discursos coloniais sobre a África.

${ }^{7}$ A matrilinearidade é aqui compreendida como o sistema de parentesco, de filiação através do qual somente a ascendência (família) da mãe é tida em consideração para a transmissão do nome, dos benefícios ou do status de se fazer parte de um clã ou classe, enquanto na patrilinearidade a ascendência considerada é a paterna.
} 
desconstruir a visão de progresso associada ao patriarcado e a visão de uma organização primitiva ligada ao matriarcado e à matrilinearidade e também sua utilização dos mesmos conceitos europeus presentes nestas pesquisas para fundamentar sua oposição a estas interpretações.

Analisando as teorias sobre o patriarcado propostas por diferentes autores do século XIX, Diop ${ }^{8}$ tem o intuito de mostrar que faltam bases científicas que provem a superioridade das sociedades patriarcais e busca dissociar o matriarcado de algo atrasado e primitivo, bem como sua oposição em relação ao patriarcado. Exemplificaremos a crítica estabelecida pelo autor a partir dos pressupostos das pesquisas realizadas por dois desses autores, Bachofen e Engels.

A teoria de Bachofen ${ }^{9}$ afirma que a paternidade era desconhecida nos grupos com menor complexidade socioeconômica e isto colocava as mulheres em uma situação de poder dentro desses grupos. Para Bachofen ${ }^{10}$, no início do desenvolvimento humano, os homens viviam em barbárie e em promiscuidade sexual e por isso a descendência reconhecida só poderia ser a materna, posto que a paterna era questionável. Essa seria a primeira fase, o estágio de promiscuidade, onde se identifica a primazia do direito materno.

Na segunda fase, teria existido o estágio do matriarcado, onde é estabelecida a monogamia e a mulher passa a ter o domínio sobre a família e o Estado. Para confirmar que realmente houve um período de dominação das mulheres, o autor recorre à existência e culto de divindades femininas, acreditando que essa representação simbólica retratava um antigo domínio político das mulheres. Para ratificar sua proposição, Bachofen ${ }^{11}$ aponta um maior culto realizado à lua, ligada às mulheres, do que ao sol, divindade ligada aos homens. Fazendo uso de um sistema religioso e ideológico, atribui características femininas não apenas à lua, mas também à noite, escuridão, morte, tristeza, em contraposição às características masculinas associadas ao sol, luz, dia, criação e alegria. Com estas atribuições já busca claramente demonstrar a preponderância do masculino sobre o feminino.

A terceira fase teria sido alcançada com o estágio do patriarcado, que se inicia quando os homens passam a reconhecer sua importância para a reprodução da espécie e tomam consciência da paternidade. Inicia-se uma nova forma de casamento e organização, agora com a dominação masculina.

\footnotetext{
${ }^{8}$ DIOP. Cheik Anta. The cultural unity of Black Africa - the domains of patriarchy and of matriarchy in classical antiquity. Westbourne, Karnak house, 1989.

${ }^{9}$ BACHOFEN, JJ. El matriarcado. Madri: Akal universitária, 1987.

${ }^{10}$ Ibidem.

${ }^{11}$ BACHOFEN, JJ. El matriarcado. Madri: Akal universitária, 1987.
} 
Friedrich Engels ${ }^{12}$ também se dedica a analisar as formas de organização dos primeiros grupos humanos e a compreender a características e a presença do matriarcado e do patriarcado nessas sociedades. Para analisar as mudanças nas formas de organização das sociedades, bem como no desenvolvimento das relações de parentescos, Engels propõe uma divisão em três momentos principais: o estado selvagem, a barbárie - que denomina como estágios pré-históricos de cultura - e a civilização.

No que tange a organização familiar, Engels ${ }^{13}$ aponta, no período da barbárie, que os grupos sociais se organizavam em famílias poligâmicas, chamadas por ele de famílias cosanguíneas, sendo retratadas como a primeira noção de família, em termos de parentesco, que teria surgido. Nesta organização, excetuando-se apenas pais e filhos, os outros parentes como irmãos, irmãs, primos e primas, mantinham relações sexuais entre si, e por isso estes eram maridos e mulheres uns dos outros.

A segunda organização familiar foi denominada de família punaluana ${ }^{14}$, onde não existem mais relações carnais entre irmãos e irmãs. Na chamada família sindiásmica ${ }^{15}$, já se observa o estabelecimento do matrimônio entre homens e mulheres, mas identifica-se a existência da poligamia, permitida apenas entre os homens. Em um terceiro momento neste processo de organização familiar, esta passa a ser monogâmica e baseada na matrilinearidade. Essa forma de organização é vista por Engels como uma forma de evolução da sociedade, até se chegar a um momento neste processo onde esta família monogâmica onde o homem conquista o papel principal e essa figura paterna passa a ser dominante na relação familiar. Surge assim o patriarcado, onde o homem possui grande poder de controle sobre sua esposa e sua família.

A partir da análise destes autores sobre a questão da organização social matriarcal e patriarcal, observamos que os mesmos defendem o processo que leva da organização matriarcal à patriarcal como um progresso universal vivido pelas sociedades, como uma evolução, considerando as estruturas sociais matrilineares como retrógradas.

Para embasar sua crítica em relação a esses estudos antropológicos coloniais do século XIX,

\footnotetext{
${ }^{12}$ ENGELS, Friedrich. A origem da família, da propriedade privada e do Estado. Rio de Janeiro: Ed. Civilização brasileira, 1984.

${ }^{13}$ ENGELS, Friedrich. A origem da família, da propriedade privada e do Estado. Rio de Janeiro: Ed. Civilização brasileira, 1984.

${ }^{14}$ Estágio de organização da família onde são instituídas as gens, que podem ser entendidas como um círculo fechado de parentes relacionados pela consanguinidade, diretamente relacionada a linhagem materna, não sendo permitido que seus membros casem uns com os outros.

${ }^{15}$ Forma familiar que se caracteriza pelo matrimônio entre pares, onde o vínculo conjugal poderia facilmente ser dissolvido por uma das partes, mantendo a importância da linhagem feminina. É considerada por Engels um estágio de evolução, que permitirá o surgimento da família monogâmica.
} 
Diop $^{16}$ argumenta que o matriarcado e o patriarcado na verdade se constituem ao mesmo tempo, porém em diferentes espaços, buscando assim mostrar que a organização matriarcal não é universal. Para tanto, trabalha com a influência da ecologia sobre a organização social, atribuindo a esta fatores externos. Existiriam duas lógicas de organização socioeconômicas opostas pela interação do homem com os meios ambientais. Apresenta a hipótese de dois "berços" de desenvolvimento humano, que seriam o do norte, berço setentrional, e o do sul, berço meridional, tendo como ponto de divisão a bacia do Mediterrâneo.

O berço setentrional, por apresentar um caráter nômade devido ao ambiente árido, estando ligado aos povos indo-europeus, englobando a Europa mediterrânea e o Oriente Médio semita, foi favorável à organização patriarcal, pois a mulher era vista como um fardo que o homem carregava, tendo sua função reduzida à procriação. Devido ao clima bastante rigoroso e ao solo gelado, a vida estava em constante perigo e prolongou-se a dependência da caça, pois a agricultura não pode se desenvolver. Isso fez também com o homem necessitasse usar muitas vestimentas e habitar lugares fechados.

Estas características teriam sido responsáveis pelo desenvolvimento de hábitos de competição, de conquista, práticas materialistas, um culto a propriedade privada e uma visão intolerante em relação ao outro. Fundaram-se sociedades patricêntricas ${ }^{17}$, falocráticas ${ }^{18}$, tendo o lugar central ocupado pelo homem, que tiveram uma agressividade herdada pelo modo de vida nômade, que desencadeou os ideais de guerra, conquista e violência. O homem assim desenvolve um sentimento de solidão moral e material e uma posição individualista.

Já o berço meridional, que engloba a África, tendo como base de desenvolvimento sociedades agrárias, devido à vegetação existente, possibilitou o processo de sedentarização, tinha a mulher como base de uma função central, pois era ela que trabalhava na agricultura enquanto os homens caçavam, sendo assim sociedades favoráveis à organização matriarcal. As propriedades eram coletivas e a organização social baseava-se em uma vida comunitária.

Caracterizava-se por ser uma sociedade uterocêntrica ${ }^{19}$, pela policonjugalidade ${ }^{20}$, pela matricentricidade ${ }^{21}$ e por uma concepção solidária de vida em comunidade, o que tornava possível a xenofilia e a percepção positiva da alteridade, pois o outro não era visto como inimigo.

\footnotetext{
${ }^{16}$ DIOP. Cheik Anta. The cultural unity of Black Africa - the domains of patriarchy and of matriarchy in classical antiquity. Westbourne, Karnak house, 1989.

${ }^{17}$ Tipo de sociedade onde o homem é considerado o centro, a base da família.

${ }^{18}$ Sociedade onde se busca justificar a supremacia masculina.

${ }^{19}$ Expressão utilizada na obra de Carlos Moore, para referir-se às sociedades onde a principal forma de organização ocorre pelos laços de maternidade. MOORE, Carlos. Racismo e sociedade: novas bases epistemológicas para entender o racismo. Belo Horizonte: Mazza Edições, 2007. 320 p.
} 
A mulher era emancipada da vida doméstica e possuía uma posição de destaque na comunidade. Através desta organização matricêntrica foram passados valores morais e éticos fundamentados na paz e na cooperação social. Portanto, neste berço de desenvolvimento não era encontrado um sentimento individualista e nem mesmo a agressividade presente no berço de desenvolvimento setentrional.

Nas sociedades de organização matrilinear, o poder da mulher estava baseado em seu papel econômico, e a herança biológica da mãe era mais forte e mais importante que a do pai. A mãe possuía um sacro poder e sua autoridade era ilimitada. Todos os direitos políticos eram transmitidos pela mãe e a herança era proveniente do tio materno e não do pai. Nestas sociedades, segundo Diop, era a mulher que recebia o dote no casamento, podendo repudiar seu marido a qualquer momento. $\mathrm{O}$ homem era quem levava seu clã para viver junto da mulher, pois era esta quem contribuía substancialmente para a economia.

Diop parte de uma análise da macro-história, analisando grandes reinos e impérios para demonstrar sua proposta, considerando a autoridade econômica e política exercida por rainhas que governaram de forma autônoma ou junto a seus filhos e maridos, como são casos que ocorrem nas civilizações egípcia e kushita. Acredita, portanto, que o matriarcado está diretamente ligado à filiação matrilinear, se apresentando como um sistema de colaboração e desenvolvimento harmonioso entre os sexos, com certa preponderância da mulher.

Desta forma, observando a produção intelectual de Diop, é possível percebermos sua busca por mostrar o matriarcado como base da unidade cultural africana, ao mesmo tempo em que nos é perceptível a relação de sua pesquisa como uma resposta aos estudos antropológicos do século XIX sobre a África, em seu uso de categoria de análise similares às utilizadas por estes antropólogos para entender a organização social própria que se desenvolve no continente africano, bem como na busca por demonstrar uma não universalização do matriarcado como forma de evolução das sociedades.

Uma importante interlocutora da obra de Cheik Anta Diop, Elisa Larkin do Nascimento ${ }^{22}$ defende que a humanidade se iniciou na África e que os africanos foram os primeiros a construírem civilizações humanas que serviram como base para o desenvolvimento da civilização

\footnotetext{
${ }^{20}$ Relação vivencial e conjugal estabelecida, no âmbito de um grupo social, entre uma mulher e diferentes homens, assim como entre um homem e diferentes mulheres.

${ }^{21}$ Forma de organização que tem como base fundamental a unidade matricêntrica, que se configura como a menor unidade de parentesco e como uma menor unidade autônoma de produção, cujos laços são definidos a partir da maternidade. Esta maternidade não se caracteriza apenas como a de caráter biológico, mas como parte da estrutura de uma organização social que tem como base a ideologia que todos aqueles que estão inseridos em uma unidade matricêntrica estão ligados por laços maternos.

${ }^{22}$ NASCIMENTO, Elisa Larkin. A matriz africana no mundo. Rio de Janeiro: Editora Selo Negro, 2008.
} 
ocidental. Essas civilizações africanas tinham como principal característica a organização matrilinear, que passou a ser vista como uma forma primitiva de organização, pois por um longo período tentou-se provar a origem branca e europeia do ser humano, já que a ideia do negro ser o primeiro humano a habitar a Europa não era aceita. Isso se explica pelo fato do africano ser considerado como inferior aos europeus ainda no século XX e o próprio termo civilização não ser utilizado para designar as sociedades antigas que se desenvolveram na África ${ }^{23}$.

Para Nascimento ${ }^{24}$, essa organização matrilinear não consistia em um domínio da mulher sobre o homem, mas sim em uma divisão dos privilégios e responsabilidades, fazendo com que houvesse um equilíbrio na organização do Estado. A autora, bem como Diop, busca estabelecer uma análise crítica em relação à visão do patriarcado como forma de evolução na organização social e também parte da utilização de conceitos europeus para analisar as sociedades africanas, seguindo uma concepção de que as sociedades com governos centralizados teriam alcançado um maior grau de desenvolvimento, tal quais as civilizações que se desenvolveram no continente europeu, considerando, portanto desta forma, o matriarcado como forma de organização onde as mulheres detém um poder político e econômico autônomo.

Analisando os estudos realizados sobre as sociedades matrilineares, Isabel Casimiro ${ }^{25}$, até os anos 70-80 do século XX, ainda são carregados de uma visão bastante preconceituosa, haja vista o modelo de organização social patrilinear vigente e ainda entendido como superior em uma escala de evolução desta organização. A partir dos estudos pós-coloniais, que ganham força a partir da década de 80 , começa se estabelecer uma visão desconstruída dos padrões de organização social e é possível observar análises mais críticas em relação às sociedades matrilineares.

Nessas sociedades haveria um maior espaço social e político concedido às mulheres, onde estas teriam uma maior autonomia e autoridade formal em rituais e nas políticas locais, bem como no controle de rendimento e nas decisões referentes às relações familiares. A matrilinearidade era compreendida como uma oposição à patrilinearidade, enquanto que, de fato, nas sociedades matrilineares não existe uma dominação feminina, mas status sociais que se complementam e levam a uma equivalência social. Esta organização social estaria ligada às relações econômicas existentes, sendo característica de sociedades agrárias, e tendo sido estabelecida em regiões da África austral e central, da África Ocidental e da Indonésia.

\footnotetext{
${ }^{23}$ Elisa Larkin aponta que o significado da palavra civilização é utilizado relacionando-se sua origem às antigas sociedades que se desenvolveram na Mesopotâmia, apesar de indícios e pesquisas recentes apontarem que houve uma evolução anterior no continente africano, além deste ter sido palco de uma primeira revolução - a passagem da caça e da coleta à agricultura.

${ }^{24}$ Ibidem.

${ }^{25}$ CASIMIRO, Isabel Maria. Paz na Terra, Guerra em Casa. Série Brasil \& África coleção Pesquisas 1, Pernambuco: Editora da UFPE, 2014.
} 


\section{O matriarcado na obra de Ifi Amadiume - revendo conceitos a partir de conhecimentos} endógenos

Ifi Amadiume é nigeriana, doutora em antropologia social e considerada por sua contribuição intelectual nas formas de pensar os conceitos de sexo e gênero nas sociedades africanas e o lugar da mulher na história e na cultura. Sua obra aqui analisada foi editada em 1997 nos Estados Unidos e reeditada em $2001^{26}$. A obra reúne estudos realizados pela autora entre 1989 e 1994 e suas reflexões teóricas sobre as sociedades africanas em particular por ela analisadas, bem como uma análise crítica do legado de Diop em relação aos estudos sobre o matriarcado e sua base para uma unidade cultural africana.

Amadiume destaca a importância da compreensão das relações econômicas e suas implicações sociais nas sociedades africanas. Para tanto, aponta a necessidade de ter estabelecido em suas pesquisas uma metodologia que compreendesse o aspecto multidimensional da sociedade em suas estruturas, com a base em suas instituições sociais e sua economia, relacionada a uma superestrutura envolvendo uma política dialética de cultura e ideologia.

A autora evidencia o problema existente no uso de termos e expressões europeias para civilizações e culturas não europeias. Reconhecendo a importância da produção intelectual de Diop, porém estabelece com essa uma análise crítica, tendo como foco a questão de Diop embasar suas pesquisas nas grandes civilizações, com sistemas políticos centralizados como tipo ideal e suas culturas como civilização clássica, não considerando as relações existentes nas pequenas cidades e vilas, o uso de conceitos e explicações ocidentais, além do fato de Diop partir de fatores e debates exógenos para considerar a organização matriarcal e matricentrada na África, acreditando ser o matriarcado baseado em regras de herança e sucessão e estar diretamente relacionado à matrilinearidade.

Segundo Amadiume ${ }^{27}$, na teoria desenvolvida por Diop, os valores morais na política são tão importantes quanto o modo de produção, estando este ligado as condições materiais de vida, diretamente relacionadas à organização matriarcal e patriarcal. Para Diop, o matriarcado se caracterizaria como um modelo pacifista, por sua relevante influência na política, economia e religião, enquanto o modelo político e econômico Greco-romano seria baseado em valores militares e de violência e competitividade.

\footnotetext{
${ }^{26}$ A obra da autora que será analisada é Re-inventing Africa: Matriarchy, Religion and Culture. Interlink Publishing Group, 1997.

${ }^{27}$ AMADIUME, Ifi. Re-inventing Africa: Matriarchy, Religion and Culture. Interlink Publishing Group, 1997.
} 
O matriarcado para autora ocorre através do papel que a mulher assume enquanto mãe, dentro de uma unidade matricêntrica, sendo esta definidora da cultural matriarcal. O poder exercido pela mulher nas sociedades africanas derivava da importância sagrada que era concedida à maternidade, que era visto como algo quase divino, diferenciando o status e a experiência social das mulheres africanas em relação às europeias. $\mathrm{O}$ âmbito familiar não era assim restrito, como na sociedade patriarcal, ao âmbito doméstico.

A matrifocalidade ${ }^{28}$ é entendido como princípio organizador da sociedade, e só pode ser compreendido enquanto tal considerando as questões estruturais endógenas da mesma. 0 princípio matriarcal não estaria ligado a questões como baixo status econômico, ausência de homens ou na exclusão econômica das mulheres. O matriarcado está ligado a uma estrutura matricêntrica de organização social, que tem na mulher a sua unidade central e mais relevante.

Em sua pesquisa, Amadiume $e^{29}$ parte de uma análise que considera uma sociedade africana em particular, a sociedade Nnobi, uma comunidade do grupo Igbo, com localização no atual território da Nigéria. Partindo deste estudo de caso, a autora observa a presença da estrutura matricêntrica e do matriarcado em diferentes sociedades africanas. Sua conclusão pode ser relacionada ao fato de sua aproximação com o pensamento afrocêntrico, além sua relação de grande admiração à obra de Cheik Anta Diop.

Nesta sociedade, observa que a unidade de produção está ligada às relações de produção. Aqueles que se alimentam daquilo que foi produzido em uma unidade familiar compartilham então do espírito que emana da maternidade. Todos se encontram ligados como filhos de uma mesma mãe, representada na entidade feminina denominada Idemili. Todas as mães são representantes desta entidade na sociedade. A matricentricidade ${ }^{30}$ está presente desde o mito de origem, passando pelo domínio da casa até a organização econômica da produção.

A sociedade se encontra dividida em um sistema dual de sexos, um com status masculino e outro com status feminino, na classificação cultural de gênero. O componente desta sociedade classificado como feminino seria formado pela mãe e seus filhos e este fato o distinguiria do componente masculino.

Neste sistema dual de sexos da sociedade Nnobi, foi possível observar a oposição binária existente entre os papeis de mkpuke e obi. O primeiro possuía um status feminino, representado pela unidade matricêntrica, sendo a menor unidade de parentesco e a menor unidade de

\footnotetext{
${ }^{28}$ Matrifocalidade é aqui compreendido como um conceito que designa um grupo doméstico centrado na mãe, sendo o papel assumido pelo pai secundário.

${ }^{29}$ AMADIUME, Ifi. Re-inventing Africa: Matriarchy, Religion and Culture. Interlink Publishing Group, 1997.

${ }^{30}$ Caracteriza-se por uma sociedade centrada no símbolo da mãe/mulher.
} 
produção. Sua unidade de composição estava relacionada à casa e era autônoma, possuindo seu próprio local de cultivo. Sua ideologia era matriarcal, baseando-se em uma ideia de maternidade comum, a ideologia do umunne, com força moral e valores de coletivismo, compaixão e paz.

Já o papel de obi era relacionado ao gênero masculino de acordo com a classificação cultural, no entanto, em termos de sexo biológico poderia ser ocupado tanto por um homem quanto por uma mulher. A posição pode ser ocupada pelo marido (dibuno) ou pelo primeiro filho (diokpala). Sua unidade de composição era a família, que poderia abranger uma ou mais unidades matricêntricas. Era economicamente dependente da produção realizada pela unidade mkpuke e possuía uma ideologia patriarcal, conhecida como umunna, com valores de competitividade, masculinidade, força e violência.

Observamos aqui alguns pontos importantes a serem considerados. Primeiramente, a partir das ideologias do umunne e umunna, vemos que o matriarcado e o patriarcado se encontram convivendo juntos na sociedade Nnobi, estabelecendo uma relação dialética. Além disso, também é possível observar que o papel de obi poderia ser exercido por uma mulher, caso esta fosse a primeira filha. Ainda, uma primeira filha que também fosse mãe, assumiria o papel de mkpuke, mesmo que também tivesse o papel de obi, e ainda desta forma seria culturalmente classificada como de gênero feminino. Visto isto, torna-se claro que, ao contrário da organização familiar ocidental, o sexo biológico não é definidor dos papeis sociais que serão assumidos pelo homem e pela mulher no caso supracitado.

A partir deste estudo, Amadiume ${ }^{31}$ aponta que o conceito de matriarcado não é o de um sistema que abrange uma totalidade, como o de o governo central em uma sociedade, mas um sistema estrutural em justaposição com outro sistema em uma estrutura social. A unidade matricêntrica não é apenas uma unidade de produção autônoma, mas uma unidade ideológica, que gera um código moral distinto, valores de compaixão, amor e paz, derivados da maternidade compartilhada.

A legitimidade do poder exercido pelas mulheres transcende a esfera doméstica e chega à esfera pública, onde a mulher exerce um poder de governo e jurídico dentro de suas comunidades, o que não representa necessariamente um poder de dominação central e totalitário na sociedade. O matricentrismo também não representa a ausência do poder político central exercido pelo homem, nem uma simples afirmação dos direitos da mãe pelos laços uterinos, mas vai além, na esfera do poder político e jurídico exercido pelas mulheres fora do âmbito doméstico.

\footnotetext{
${ }^{31}$ AMADIUME, Ifi. Re-inventing Africa: Matriarchy, Religion and Culture. Interlink Publishing Group, 1997.
} 
A matrilinearidade não é definidora do matriarcado, podendo este existir em sociedade patrilineares. Para Amadiume ${ }^{32}$, existe uma justaposição entre estes sistemas, existindo, por exemplo, sociedades matriarcais em que as autoridades políticas são homens, como as sociedades egípcias e kushita na antiguidade, e também uma convivência entre o matriarcado e o patriarcado, como no caso da sociedade Nnobi.

Ainda no debate sobre a questão da matrilinearidade, e voltando a sua análise para obra de Diop, Amadiume ${ }^{33}$ aponta a concepção de um triângulo matriarcal, onde o poder passa da mãe para o filho, que dentro da matrilinearidade é tido como o tio, que assume um importante papel. No entanto ele é filho, irmão, marido e também pai, tanto quanto tio. Portanto, é através da mãe, e não do tio, que o status e os direitos dos homens são transmitidos. A unidade matricêntrica assegura e transmite os bens.

A paternidade é vista pela autora como uma construção social e disputável, enquanto as relações de maternidade criam laços até entre as crianças com diferentes pais. É a primazia dos laços uterinos presente no ambiente doméstico que possibilita esta construção. A figura do pai não é a base do status da criança, sendo a matrifocalidade o laço mais forte, estabelecendo-se em sua força moral.

Desta forma, para a autora, a unidade matricêntrica não está baseada somente em uma unidade de produção autônoma que confere um status político e social as mulheres que ultrapassa o ambiente doméstico, mas é também uma unidade ideológica. A matricentricidade é, nas sociedades africanas, uma construção cultural, mesmo tendo sua base no papel reprodutor da mulher. Essa construção tem em sua ideologia os valores de amor, coletivismo e proteção. Assim sendo, a matrilinearidade já se apresenta como o foco do poder da mulher, mesmo considerandose o papel do tio materno, pois este só o assume por sua descendência materna. Esse tio não apenas detém esta função, sendo ele no âmbito familiar também um irmão, um marido, um filho e um pai. Portanto, o matriarcado compreendido como a soberania política autônoma de mulheres não representa a fundamentação da elevada importância social que a elas é conferida.

\section{Oyeronke Oyewumi: uma reflexão sobre a conceitualização de gênero nas sociedades} africanas

Oyeronke Oyewumi é nigeriana e atualmente leciona Sociologia na Universidade Estadual de Nova York em Stony Brook, ministrando aulas sobre gênero, globalização e teoria feminista. Suas

\footnotetext{
${ }^{32}$ Ibidem

${ }^{33}$ AMADIUME, Ifi. Re-inventing Africa: Matriarchy, Religion and Culture. Interlink Publishing Group, 1997.
} 
pesquisas visam discutir a experiência africana a partir de conceitos e epistemologias que estejam ligados a sua cultura, considerando os fatores endógenos ao continente, e assim como Amadiume, reconhecendo que as interpretações produzidas a partir de conceitos e categorias europeias não dão conta de compreender as especificidades na organização social e política e nas ideologias presentes nas sociedades do continente africano.

Em sua principal obra, lançada em 1997, discute o conceito de gênero presente na narrativa ocidental e argumenta que existe uma lógica cultural no Ocidente que categoriza os papeis sociais de acordo com um determinismo biológico ${ }^{34}$. Os gêneros masculino e feminino são diretamente associados ao sexo biológico e determinam os papeis exercidos por homens e mulheres na sociedade. Para autora, essas categorias foram impostas nas leituras e interpretações realizadas sobre as sociedades africanas.

Sua pesquisa parte da sociedade yorubá pré-colonial, onde constata que nesta sociedade, o sexo biológico não se constituía em uma base para hierarquia social e a distinção entre homens e mulheres não era feita a partir da anatomia. O gênero não era, portanto, o principio organizador desta sociedade até a colonização europeia. Essa característica podia ser também identificada na própria linguagem. Na língua yorubá não existe uma tradução para feminino e masculino, pois existiam poucas associações relacionadas a construção social com essas categorias.

O princípio organizador da sociedade era a senioridade, baseada na idade cronológica, sendo este não relacionado ao gênero, podendo estar o centro do poder da família com um homem ou uma mulher. Esse princípio baseado na senioridade é fluido e dinâmico, ao contrário daquele baseado no gênero, que se apresenta de forma rígida.

Oyewumi ${ }^{35}$, analisando os termos utilizados nas traduções realizadas da língua yorubá para o inglês, aponta que a tradução feita do termo iyawo como esposa, não corresponde a seu verdadeiro significado na língua yorubá. O termo oko, que no inglês foi traduzido como marido, tampouco o pode ser associado quando se analisa a organização social yorubá. Os termos oko e iyawo eram usados para distinguir aqueles que integravam a família por consanguinidade daqueles que nela teriam entrado a partir do casamento, não estando relacionados com os gêneros masculino ou feminino, podendo ser utilizados tanto para homens quanto para mulheres.

Partindo desta consideração, é possível observar que a hierarquia presente na organização social dada a partir da utilização destes termos não se baseia nas relações de gênero. Aqueles denominados pelo termo oko, ocupavam uma posição superior em relação aos denominados

${ }^{34}$ A obra a qual fazemos referência é The Invention of Women: Making an African Sense of Western Gender Discourses, University of Minnesota Press, Minneapolis. 1997.

${ }^{35}$ Ibidem 
como iyawo, pois os primeiros já eram membros da família por consanguinidade. As mulheres englobadas na categoria oko estavam em uma posição superior às mulheres iyawo. No entanto é importante considerar a fluidez existente nesses papeis sociais, pois novos membros sempre são incorporados à família, e por isso as posições sociais se encontram em constante mudança.

Ainda tratando-se da linguagem, a autora nos fornece o exemplo do termo oba, que significava governante, sendo uma posição social que poderia ser ocupada por um homem ou uma mulher. No entanto, após a colonização, o termo passou a ser usado para se referir a rei. Esse exemplo atesta a hipótese de Oyewumi de que as categorias de gênero são uma construção social e cultural da sociedade patriarcal que se desenvolve no Ocidente.

A identidade mais importante assumida pelas mulheres nas sociedades africanas era a de ser mãe. Nas famílias africanas o princípio organizador é o consanguíneo e não o conjugal, sendo as relações de sangue que constituem o núcleo familiar. O laço mais importante desses arranjos familiares está dentro do fluxo da família da mãe. Assim sendo, o parentesco é definido a partir de laços uterinos e dentro das relações sociais estabelecidas nessas sociedades, acreditava-se que a mulher possuía poderes sagrados devido à maternidade.

A autora ${ }^{36}$ atribui à questão da matrifocalidade, presente na maior parte dos sistemas familiares africanos, o fato da mãe ser o centro a partir do qual as relações familiares são delineadas. Em cada família, os membros seriam agrupados em unidades, que em yorubá recebiam a designação de omoya, formadas pela mãe e pelas crianças que seriam irmãos a partir de laços uterinos. A ligação existente entre os membros desta unidade denominada omoya seria dada pelo amor incondicional derivado da mãe. Um exemplo desta ligação se encontra no fato de que os primos maternos eram considerados mais próximos, enquanto irmãos uterinos, do que irmãos que tivessem o mesmo pai, porém não a mesma mãe. Observa-se desta forma, que as relações estabelecidas pelo omoya transcendiam o âmbito doméstico, detendo grande consideração na organização social e devendo ser privilegiadas e protegidas acima de outras.

Para Oyewumi:

\footnotetext{
“Consequentemente, omoya é a categoria comparável na cultura lorubá à irmã nuclear na cultura euro-americana branca. A relação entre irmãos de ventre, como aquela das irmãs da família nuclear, é baseada em uma compreensão de interesses comuns nascidos de uma experiência compartilhada. A experiência partilhada definidora, que une os omoya em lealdade e amor incondicional, é o ventre da mãe. A categoria omoya, diferentemente
}

\footnotetext{
${ }^{36}$ OYĚWÙMÍ, Oyèrónké. Conceituando o gênero: os fundamentos eurocêntricos dos conceitos feministas e o desafio das epistemologias africanas. Tradução para uso didático de: OYĚWÙMÍ, Oyèrónké. Conceptualizing Gender: The Eurocentric Foundations of Feminist Concepts and the challenge of African Epistemologies. African Gender Scholarship: Concepts, Methodologies and Paradigms. CODESRIA Gender Series. Volume 1, Dakar, CODESRIA, 2004, p. 1-8 por Juliana Araújo Lopes.
} 
de irmã, transcende o gênero". ${ }^{37}$

A independência e autonomia das mulheres poderia ser observada para além da esfera doméstica, estando as mulheres presentes em atividades econômicas e também na esfera política, ocupando diferentes cargos. De acordo com Jìmí Adésínà ${ }^{38}$, em sua análise sobre a obra de Oyewumi, as mulheres controlavam os mercados e o comércio de longa distância na sociedade yorubá pré-colonial. Sua presença também podia ser observada em cargos políticos de diferentes níveis.

Desta forma, a partir das reflexões de Adésínà ${ }^{39}$ sobre as obras de Amadiume e Oyewumi, observamos que as concepções e discursos propostos pelas autoras acerca do matriarcado e da matricentricidade apresentam novos elementos que não estão apenas relacionados a um entendimento da questão de gênero que vise ultrapassar as explicações e determinações biológicas. As ideias propostas pelas autoras nos levam a refletir sobre uma outra forma de organização social e de concepção da maternidade e do papel social exercido pela mulher.

Além disso, essa análise nos possibilita pensar em como as categorias ocidentais relacionadas a gênero e a uma determinada concepção de organização familiar não dão conta de compreender ou definir a organização social e cultural das sociedades africanas pré-coloniais. A dualidade entre masculino e feminino e os papeis sociais assumidos pelo homem e pela mulher, marcados por suas características biológicas, não são capazes de interpretar as culturas africanas sem que existam distorções.

Segundo Adésínà ${ }^{40}$,

"Matrifocality and matricentric kinship systems offer different bases for thinking through the concept and meaning of identity. The principle of matrifocality is not only in transcending the bio-logic (biological determinism) that maps social attributes inexorably on biology but in its implications for identity and inclusive social order".

Pensar na matricentricidade e na matrilinearidade como uma forma de organização que era comum as sociedades africanas anteriormente as dominações islâmica e europeia, nos permite debater sobre a consideração de uma unidade cultural partilhada por essas sociedades, e a partir desta concepção, teorizar um discurso acerca de uma identidade africana que seja a base de

\footnotetext{
${ }^{37}$ OYĚWÙMÍ, Oyèrónké. Conceituando o gênero: os fundamentos eurocêntricos dos conceitos feministas e o desafio das epistemologias africanas. Tradução para uso didático de: OYĚWÙMÍ, Oyèrónké. Conceptualizing Gender: The Eurocentric Foundations of Feminist Concepts and the challenge of African Epistemologies. African Gender Scholarship: Concepts, Methodologies and Paradigms. CODESRIA Gender Series. Volume 1, Dakar, CODESRIA, 2004, p. 1-10 por Juliana Araújo Lopes, p.7.

${ }^{38}$ ADESINA, Jimi. "Re-appropriating Matrifocality: Endogeneity and African Gender Scholarship. African Sociological Review 14 (1). 2010 p. 9.

39 ADESINA, Jimi. "Re-appropriating Matrifocality: Endogeneity and African Gender Scholarship. African Sociological Review 14 (1), 2010.

${ }^{40}$ Ibidem, p. 15.
} 
ligação entre aqueles que têm suas raízes nesse continente ${ }^{41}$.

\section{Repensando a concepção de gênero e o papel social da mulher a partir de uma abordagem} afrocentrada

Repensar as questões relacionadas a gênero e a matrilinearidade no contexto das sociedades africanas, considerando seus sistemas culturais, históricos e sociais a partir de análises e conceitos que possam ser formulados através dos fatores endógenos presentes nestas sociedades, representa uma ressignificação na compreensão da história do continente e na concepção da formação de uma identidade que se forma com um estreitamento de laços dados com a consideração de uma visão de africanidade.

Essa visão de africanidade é pensada a partir de valores e concepções partilhadas pelos africanos $^{42}$ e que formam a base para uma identidade cultural ${ }^{43}$ africana. Busca-se posicionar o africano como protagonista de sua história. Essas raízes que são buscadas na história e cultura africanas são parte essencial na construção dessa unidade não só para os que permanecem vivendo no continente africano, mas para todos aqueles descendentes da diáspora africana.

Desta forma, pensar em uma identidade cultural africana a partir do afrocentrismo, é compreender que existe uma experiência com base em valores e elementos culturais africanos, que são formadores de uma unidade cultural, que são transmitidos a partir de hábitos, costumes, crenças, filosofias, comportamentos, religião, pensamento, e que necessitam ser interpretados a partir de uma concepção africana, pois as interpretações eurocentradas não dão conta da autenticidade de seu significado.

Isso não significa que essa noção de uma uniformidade na análise de elementos e contribuições africanas negue a diversidade. O afrocentrismo é pensado a partir da pluralidade, pois este não parte de uma imposição de sua forma de pensar. O pensamento afrocentrado

\footnotetext{
${ }^{41}$ Possuir as raízes no continente africano engloba não somente aqueles que vivem em África, mas também os africanos em diáspora, que buscam suas origens neste continente para construção de uma identidade que tenha como base uma unidade cultural africana. Uma das bases dessa unidade é a organização matrilinear presente nas sociedades africanas.

${ }^{42} \mathrm{Na}$ perspectiva afrocêntrica o africano é aquele que sustenta o fato de seus ancestrais terem vindo para América e para diferentes partes do mundo e reivindica esse parentesco por ser conscientemente africano. Não se trata apenas daqueles estão vivendo no continente, mas de todos que também estão fora dele, em diáspora, mas que lutam pelo reconhecimento da agência africana e contra qualquer forma de opressão humana. Ver ASANTE, Molefi Kete. Afrocentricidade: notas sobre uma posição disciplinar. In: NASCIMENTO, Elisa Larkin (org). Afrocentricidade: uma abordagem epistemológica inovadora. São Paulo: Editora Selo Negro, 2009, pp. 93-110, pp. 104-105.

${ }^{43}$ Utilizamos aqui a concepção de identidade cultural proposta por Stuart Hall, considerando que esta identidade enfatiza aspectos relacionados a pertença a culturas étnicas, raciais, linguísticas, religiosas, regionais e/ou nacionais. Baseia-se no sentimento de identificação com um grupo influenciado pela sua cultura. A partir do intenso processo de mudanças ocorrido nas sociedades modernas, a identidade que antes se encontrava em forte ligação com o Estado e com a nação, passa a ser descentralizada, havendo um deslocamento e a ausência de referentes fixos para construção da identidade, observando-se assim, uma pluralização das identidades. Ver HALL, Stuart. A identidade cultural na pósmodernidade. 9. ed. Rio de Janeiro: DP\&A, 2004.
} 
enfatiza a possibilidade de diálogo entre diferentes conhecimentos e reconhece e valoriza as diversas experiências presentes nas sociedades.

O afrocentrismo é entendido como uma forma de construção crítica do conhecimento, uma conscientização da necessidade de valorizar todas as experiências africanas, resistindo a uma imposição cultural e a interpretações não africanas destas. Aqueles que buscam conhecer essas experiências e estabelecer conexões a partir delas têm seus ancestrais oriundos da África para diversas partes do mundo. Como exposto por Asante,

\begin{abstract}
“Assim, a afrocentricidade reconhece e respeita a natureza transitória do eu- e não é contra o eu, mas a favor da pessoa. De fato, pode-se até declarar que a afrocentricidade se dedica fundamentalmente ao eu coletivo e, portanto, está proativamente engajada na criação e recriação da pessoa em larga escala. O que os africanos fazem no Brasil, na Colômbia, na Costa Rica, na Nicarágua, no Panamá, na Venezuela, nos Estados Unidos, na Nigéria, em Gana, em Camarões, no Congo e na França é parte de uma ascensão geral coletiva à consciência, na medida em que tenha como objetivo o processo de libertação".
\end{abstract}

O pensamento afrocêntrico tem como pressuposto a conscientização na busca pela ética da justiça, colocando-se contra toda forma de opressão humana. Busca analisar as relações humanas e suas interações a partir de uma nova perspectiva, onde o africano seja agente ${ }^{45}$ de sua própria história e onde haja a valorização dos elementos culturais africanos.

Sendo toda experiência africana relevante e digna de estudo na concepção afrocêntrica, compreender a matrilinearidade, o matriarcado e o papel social das mulheres nas sociedades africanas a partir desta abordagem trata-se não apenas de uma valorização da história e da cultura africanas, como também de uma interpretação a partir de elementos e categorias que assumem diferentes significados fora da lógica europeia ocidental, representando não apenas o ponto de vista patriarcal.

Segundo Asante,
“Em tal contexto, as mulheres não são relegadas ao segundo plano, como acontece no pensamento ocidental. Isso provém do fato de elas terem sido parte integrante de todas as culturas africanas desde o início dos tempos. Observando as sociedades africanas da antiguidade, é difícil encontrar alguma em que as mulheres não ocupassem altas posições. Por exemplo, as rainhas que governaram o Kemet, o Punt e a Núbia - e mais de quarenta governaram esse país - representam os mais antigos exemplos de governantes do sexo feminino" ${ }^{46}$.

\footnotetext{
${ }^{44}$ ASANTE, Molefi Kete. Afrocentricidade: notas sobre uma posição disciplinar. In: NASCIMENTO, Elisa Larkin (org). Afrocentricidade: uma abordagem epistemológica inovadora. São Paulo: Editora Selo Negro, 2009, pp. 93-110, p. 104.

${ }^{45}$ De acordo com Asante, “a agência é a capacidade de dispor dos recursos psicológicos e culturais necessários para o avanço da liberdade humana”. Ibidem, p. 94.

${ }^{46}$ ASANTE, Molefi Kete. Afrocentricidade: notas sobre uma posição disciplinar. In: NASCIMENTO, Elisa Larkin (org). Afrocentricidade: uma abordagem epistemológica inovadora. São Paulo: Editora Selo Negro, 2009, pp. 93-110, p. 104.
} 
Na Núbia, como exemplo das governantes do sexo feminino supracitadas, podemos mencionar as candaces $^{47}$, rainhas que assumiram o poder político na civilização meroítica, no reino Kush, que se localizava na região da África subsaariana, entre os séculos II A.C e IV D.C, representando a força da mulher como indivíduo ativo. De acordo com Harkless ${ }^{48}$, o papel social de destaque ocupado pela mulher no reino Kush pode ser explicado pela crença de que estas detinham poderes divinos, e a maternidade era vista como único laço reconhecido.

O poder político, militar e religioso detidos pelas candaces pode ser evidenciado a partir da análise de registros e inscrições reias que comprovam sua atuação, além da forma como era representada nas paredes dos templos, subordinada somente ao próprio rei e com uma destacada posição como portadora de oferendas nos túmulos.

Alberto da Costa e Silva ${ }^{49}$ confirma o elevado status conferido às rainhas-mãe afirmando que a mãe do rei possivelmente era um dos principais chefes do partido que o levara ao trono. Isso aponta para demonstrar que o elevado status social conferido a essas mulheres está diretamente relacionado ao seu papel de mãe. Ainda neste sentido, podemos citar a análise de $\mathrm{M}^{\prime}$ Bokolo ${ }^{50}$, que debatendo a questão da importância da filiação materna no reino Kush, no período meroítico, aponta o exemplo presente na estela do rei Aspelta (593-568 A.C), que declara ter recebido seus direitos hereditários de sucessão de sua mãe.

Segundo o autor, as rainhas e princesas ocupavam um lugar central no sistema monárquico do reino, onde inicialmente tinham uma participação indireta, na educação dos príncipes, na adoção da primeira esposa de seu filho, que era o rei em exercício, como conselheiras ouvidas por seus maridos e filhos, na participação na cerimônia de coroamento, e posteriormente de forma direta, quando assumiram efetivamente o poder político.

No Egito, na 25a dinastia, dinastia kushita, havia se tornado uma prática para o faraó instalar seus parentes do sexo feminino como as sumo-sacerdotisas de Amon em Tebas. Essas mulheres na verdade teriam se tornado governantes no Alto Egito. Segundo Williams e Finch (2007), foram empreendidas por elas massivas restaurações e obras públicas em Tebas e em todo Alto Egito. Seus nomes estão presentes em monumentos, edifícios e estátuas e elas são retratadas tanto como sacerdotisas quanto administradoras.

\footnotetext{
${ }^{47} \mathrm{O}$ termo candace deriva da palavra de origem meroíta KTKE ou KDKE, que significa rainha-mãe.

${ }^{48}$ HARKLESS, Necia Desiree. Nubian pharaohs and meroitic kings - the kingdom of Kush. Bloomington: Author House, 2006.

${ }^{49}$ SILVA, Alberto da Costa. A enxada e a lança - A África antes dos portugueses. Editora Nova Front, 2011 , p. 134.

${ }^{50}$ M'BOKOLO, Elikia. África negra- história e civilizações. Salvador: EDUFBA, 2009 p. 82.
} 
Na reflexão afrocêntrica, mulher e homem tem a mesma importância dentro da construção do conhecimento. Assim sendo, conhecer o status assumido pelas mulheres nas civilizações africanas clássicas contribui para percepção da existência de uma relação complementar entre o homem e a mulher, onde o papel social desta não era dado pela questão de uma hierarquia entre os gêneros, mas sim pela relevância de seu papel de mãe.

Para Nah Dove ${ }^{51}$, analisando o conceito de matriarcado a partir de uma concepção afrocentrista, a natureza do masculino e do feminino não é entendida como hierárquica. 0 homem e a mulher trabalham juntos em diferentes áreas de organização social.

Segundo a autora, "A mulher é reverenciada em seu papel como a mãe, quem é a portadora da vida e a condutora para a regeneração espiritual dos antepassados, a portadora da cultura e o centro da organização social" ${ }^{52}$ Desta forma, o conceito de mãe estaria acima de relações de gênero, sendo um título conferido à mulher, sendo sua mais importante identificação dentro da sociedade.

Buscando compreender as experiências culturais africanas a partir de conceitos que estejam a elas relacionando, visando conceber interpretações que considerem os elementos relativos a essa cultura, Oyewumi a importância de se interrogar sobre o conceito de gênero e o papel social da mulher nas sociedades africanas de uma forma onde não prevaleçam as predileções, os preconceitos, os interesses e as categorizações dominadas por um pensamento hegemônico estabelecido pelos europeus.

A autora aponta que o discurso feminista se encontra enraizado no núcleo familiar, e neste, a mulher é sinônimo de esposa. Esse discurso vem utilizando a categoria de gênero como base para reflexão acerca das questões de subordinação da mulher, a sua opressão e a desigualdade presente nas estruturas sociais. Porém este discurso não está considerando a questão de a categorização de gênero ser, antes de tudo, uma construção sociocultural. Assim sendo, a própria categoria social de mulher não é universal, e a análise a partir da categoria de gênero não é suficiente para compreender todas as formas de opressão e desigualdades presentes nas sociedades, pois existem diferentes grupos de mulheres que são afetadas por estas questões de diferentes formas, sendo, portanto necessário também considerar outras categorias, como as de raça e classe, não podendo o conceito de gênero ser abstraído do contexto social no qual se insere e nem pensado sem que esteja relacionado a outras formas de hierarquia.

\footnotetext{
51 DOVE, Nah. Mulherisma Africana - uma teoria afrocêntrica. Tradução de Wellington Agudá. JORNAL DE ESTUDOS NEGROS, Vol. 28, № 5, Maio de 1998, p. 1-26.

${ }^{52}$ Ibidem, p. 8.
} 
Debatendo sobre a não universalização do conceito de gênero, a autora aponta que o papel social exercido pela mulher nas sociedades europeias e americanas não é observado fora daquele fundamentado pela família nuclear, entendida como sendo formada por um par com gêneros bem estabelecidos, uma esposa subordinada, um marido de poder patriarcal e os filhos. A mãe é antes de tudo esposa o que parece esclarecer a expressão mãe solteira. Sendo o gênero o princípio fundamental de organização da família nessas sociedades, ele também é definidor de hierarquias, mesmo porque, dentro das famílias nucleares a classe e a raça não são normalmente variáveis.

Nas sociedades africanas, a maternidade é definida por uma relação de progênie, e não pela relação sexual com um homem, constituindo a identidade principal assumida pela mulher. Desta forma, na perspectiva africana, uma mãe por definição não poderia ser solteira, pois nestas sociedades ser mulher não é sinônimo de ser esposa.

Considerando a importância de analisar as categorias de gênero e mulher partindo de interpretações que considerem os fatores endógenos ao continente africano, refletindo sobre suas formas de organização social e política, sua história e suas experiências culturais, autoras que se dedicam a essas reflexões partindo da perspectiva do afrocentrismo, como Ifi Amadiume, Nah Dove e Oyeronke Oyewumi, buscam reconhecer a especificidade das experiências das mulheres africanas, suas ideias e seu ativismo a partir da teoria do Mulherisma Africana, onde a dimensão cultural é entendida como fundamental na análise dessas experiências.

A teoria do Mulherisma Africana (Africana Womanist) de Cleonora Hudson-Weems ${ }^{53}$ é pensada dentro da abordagem afrocêntrica e objetiva valorizar o papel das mães africanas na busca por reconstruir e criar uma integridade cultural que tenha como base os valores de harmonia, justiça, reciprocidade e equilíbrio. A valorização dessa experiência das mães africanas se coloca como um elemento central para construção de uma visão de mundo africana e uma forte base desafiadora e questionadora de valores, comportamentos e estruturas sociais nos quais estão inseridos homens e mulheres africanos.

De acordo com Hudson-Weems ${ }^{54}$, o Mulherisma Africana se trata de uma ideologia projetada para todas as mulheres de ascendência africana. Tendo como base a cultura africana, representa as lutas, as necessidades, as experiências e os desejos dessas mulheres.

Desta forma, o conceito de Mulherisma Africana reconhece as diferentes prioridades das mulheres africanas, bem como a importância de se autorreconhecer e se autodefinir. Tem sua centralidade na família e não na mulher, sendo consideradas também as questões de raça e

\footnotetext{
${ }^{53}$ HUDSON-WEEMS, Cleonora. Africana womanism: Reclaiming ourselves. Troy, Ml: Bedford, 1993.

${ }^{54}$ Ibidem, p. 24.
} 
classe, além da questão de gênero. Reconhece que a principal luta estabelecida pelas mulheres negras não está baseada na questão do empoderamento da mulher unicamente, mas se relaciona com a questão racial e o genocídio cultural. Analisar as questões de raça e classe é assim um elemento essencial que as mulheres negras possam pensar na questão de gênero.

Observamos assim, que essa busca pelo empoderamento da raça, e como consequência também o da mulher negra a partir da teoria da Mulherisma Africana parte da compreensão e reconhecimento do papel social que as mulheres tiveram na história e cultura africanas, sendo lideranças em suas comunidades, assumindo papeis de líderes espirituais, políticas e militares, para construir uma base de pensamento alternativo à cultura centrada no homem e recuperar a forma de relação complementar existente entre o homem e a mulher, onde ambos sejam igualmente empoderados.

\section{Considerações finais}

Buscamos a partir do desenvolvimento deste trabalho compreender como os conceitos de matriarcado e matrilinearidade, assim como as categorias de mulher e gênero, podem ser pensados quando analisamos as sociedades africanas em seu contexto social, histórico e cultural anterior à colonização europeia. Partindo do discurso proposto por intelectuais africanos, bem como do debate historiográfico desenvolvido sobre o tema, observamos que a mulher nestas sociedades africanas assumia um elevado status social e político, que superava seu relevante papel dentro do ambiente doméstico e chegava até uma grande influência em suas comunidades e, em muitos casos, foi observada a ocupação de elevados cargos políticos e militares.

No entanto, ao refletirmos sobre a utilização de conceitos e categorias formulados sob a ótica do pensamento e da cultura europeia ocidental, percebemos que estes em muitos casos não são capazes de dar sentido às diferentes formas de organização e papeis sociais assumidos no contexto das sociedades africanas. O uso desses conceitos e categorias feitos sem uma interpretação e reflexão que considere os fatores internos que influenciavam diretamente na organização social política e cultural destas sociedades não é capaz de conseguir de fato representá-las, reproduzindo desta forma um olhar e uma escrita sobre a África que ainda pode estar carregada por questões etnocêntricas.

Pensar a matrifocalidade presente nas sociedades pré-coloniais africanas é uma forma de valorizar as questões culturais na busca da construção de uma identidade africana, uma identidade que visa fundar-se em suas origens, que procura conhecer a unidade cultural existente na formação social em seu continente, unidade esta que não essencializa, mas que reconhece a 
diversidade. Compreender a matricentricidade como um elo cultural presente nessas sociedades recoloca os africanos e os africanos em diáspora como agentes de sua própria história, na busca não apenas de uma identidade que os una independente de sua localização, mas também na oportunidade de compreender sua história não somente pelo olhar e pela escrita do outro, mas partindo de interpretações e visões que considerem os valores morais, culturais, sociais e a história dessas sociedades a partir da análise de fatores endógenos das mesmas.

\section{Referências bibliográficas}

ADESINA, Jimi. "Re-appropriating Matrifocality: Endogeneity and African Gender Scholarship". African Sociological Review 14 (1). 2010.

AMADIUME, Ifi. Re-inventing Africa: Matriarchy, Religion and Culture. Interlink Publishing Group, 1997.

ASANTE, Molefi Kete. Afrocentricidade: notas sobre uma posição disciplinar. In: NASCIMENTO, Elisa Larkin (org). Afrocentricidade: uma abordagem epistemológica inovadora. São Paulo: Editora Selo Negro, 2009, pp. 93-110.

BACHOFEN, JJ. El matriarcado. Madri: Akal universitária, 1987.

CASIMIRO, Isabel Maria. Paz na Terra, Guerra em Casa. Série Brasil \& África coleção Pesquisas 1, Pernambuco: Editora da UFPE: 2014.

DIOP. Cheik Anta. Precolonial Black Africa: a comparative study of the political and social systems of Europe and Black Africa, from Antiquity to the Formation of modern States. Westport: Lawrence Hill \& Company, 1986.

The cultural unity of Black Africa - the domains of patriarchy and of matriarchy in classical antiquity. Westbourne, Karnak house, 1989.

DOVE, Nah. Mulherisma Africana - uma teoria afrocêntrica. Tradução de Wellington Agudá. JORNAL DE ESTUDOS NEGROS, Vol. 28, № 5, Maio de 1998, p. 1-26.

ENGELS, Friedrich. A origem da família, da propriedade privada e do Estado. Rio de Janeiro: Ed. Civilização brasileira, 1984.

HARKLESS, Necia Desiree. Nubian pharaohs and meroitic kings - the kingdom of Kush. Bloomington: Author House, 2006.

HOUNTONDJI, Paulin J. Conhecimento de África, conhecimento de africanos: duas perspectivas sobre os estudos africanos. Revista Crítica de Ciências Sociais (Coimbra), no 80, 2008.

HUDSON-WEEMS, Cleonora. Africana womanism: Reclaiming ourselves. Troy, MI: Bedford, 1993.

NASCIMENTO, Elisa Larkin. A matriz africana no mundo. Rio de Janeiro: Editora Selo Negro, 2008.

M’BOKOLO, Elikia. África negra- história e civilizações. Salvador: EDUFBA, 2009.

MOORE, Carlos. Racismo e sociedade: novas bases epistemológicas para entender o racismo. Belo Horizonte: Mazza Edições, 2007. 320 p.

OYĚWÙMÍ, Oyèrónké. Conceituando o gênero: os fundamentos eurocêntricos dos conceitos feministas e o desafio das epistemologias africanas. Tradução para uso didático de: OYĚWÙMí, Oyèrónké. Conceptualizing Gender: The Eurocentric Foundations of Feminist Concepts and the 
challenge of African Epistemologies. African Gender Scholarship: Concepts, Methodologies and Paradigms. CODESRIA Gender Series. Volume 1, Dakar, CODESRIA, 2004, p. 1-10 por Juliana Araújo Lopes.

The Invention of Women: Making an African Sense of Western Gender Discourses, University of Minnesota Press, Minneapolis. 1997.

SCHOLL, Camille Johann. Matriarcado e África: a produção de um discurso por intelectuais africanos- Cheik Anta Diop e Ifi Amadiume. Monografia para obtenção de grau de Bacharel em História. Universidade Federal do Rio Grande do Sul, Porto Alegre, 2016.

SILVA, Alberto da Costa. A enxada e a lança - A África antes dos portugueses. Editora Nova Front, 2011.

WILLIAMS, Larry e FINCH, Charles S. As grandes rainhas da Etiópia. In: SERTIMA, Ivan Van. Mulheres negras na antiguidade. New Jersey: Transaction Publishers, 2007, 13a edição, p.12-35.

Fernanda Chamarelli de Oliveira: Possui graduação em História pela Universidade do Estado do Rio de Janeiro (2005).e especialização em Orientação Educacional e Pedagógica pela Universidade Cândido Mendes (2011). Formação em Curso de Nível Médio na Modalidade Normal, com habilitação como Professora de Educação Infantil e das Séries Iniciais do Ensino Fundamental. Cursando Mestrado em História, no Programa de Pós-graduação em História Social da Cultura, na Pontifícia Universidade Católica do Rio de Janeiro (PUC - RJ). Atualmente é Professora de Ensino Fundamental - Anos Iniciais da Prefeitura da Cidade do Rio de Janeiro. Tem experiência na área do Magistério na Educação Básica como Professora de Inglês (Educação Infantil e Ensino Fundamental I), Professora de História ( $6^{\circ}$ ao $9^{\circ}$ ano do Ensino Fundamental II e $1^{\circ}$ ao $3^{\circ}$ ano do Ensino Médio) e Professora dos Anos Iniciais do Ensino Fundamental. Tem interesse em pesquisa nas áreas de Ensino de História, História da África, História de gênero e História Antiga, com foco no continente africano.

Artigo recebido para publicação em: Novembro de 2017.

Artigo aprovado para publicação em: Novembro de 2018. 